\title{
Abnormal brain scans in multiple sclerosis
}

\author{
STANLEY L. COHAN, JOSEPH FERMAGLICH \\ AND THOMAS L. AUTH
}

\begin{abstract}
From the Department of Neurology, Georgetown University, School of Medicine, Washington, D.C., 20007, U.S.A.
\end{abstract}

\begin{abstract}
SYNOPSIS A 25 year old man, with a family history of multiple sclerosis in two preceding generations, developed transient sensory changes and incoordination, initially on the left side, and then several months later on the right side in association with an elevated CSF gamma globulin. This was followed by an acute optic neuritis. During the latter episode he developed a positive brain scan which was unaccompanied by any clinical findings explained by a lesion in that area. Cerebral arteriography was normal and the brain scan returned to normal four weeks later, possibly as a result of blood brain barrier restoration. Abnormal brain scans appear to occur only during acute exacerbations of demyelinating disease, and multiple sclerosis should be part of the differential diagnosis of a positive brain scan in a person in the appropriate age range.
\end{abstract}

The occurrence of an abnormal brain scan in multiple sclerosis was first reported in 1954 (Seaman et al., 1954), but very few cases have appeared in the literature since then (Overton $e t$ al., 1965; Williams and Beiler, 1966; Bady et al., 1969; Gize and Mishkin et al., 1970; Moses et al., 1972; Antunes et al., 1974). In addition, positive brain scans have been reported in Schilder's disease (Valenstein et al., 1971) and progressive multifocal leucoencephalopathy (Mosher et al., 1971). Alternatively, Gold and Loken (1969) were unable to find positive brain scans in patients with multiple sclerosis in 852 consecutive unselected scans. The present report deals with another case of multiple sclerosis, with several interesting features, in whom a positive brain scan was found.

\section{CASE HISTORY}

A 25 year old white man, with a family history of multiple sclerosis in two preceding generations, developed impaired sensation to pain and touch in the left upper and lower extremities in May 1973. Neurological evaluation at that time revealed only left hemihypalgesia, incoordination in the left hand, and decreased position sense in the toes of the left lower extremity. The patient was admitted to Georgetown University Hospital in June 1973. Neurological examination was unchanged; skull radiography

(Accepted 12 August 1974.) series and ${ }^{99} \mathrm{Tc}$ brain scan were normal (Figure, A), electroencephalography (EEG) showed diffuse medium voltage slowing in the $5-6 \mathrm{~Hz}$ range, cerebrospinal fluid (CSF) contained no cells, sugar $50 \mathrm{mg} /$ $100 \mathrm{ml}, 41 \mathrm{mg} / 100 \mathrm{ml}$ protein with $14.7 \%$ gamma globulin (normal $<14 \%$ ). The patient was discharged and by July 1973 the incoordination, hypal-ce gesia, and loss of position sense had all improved considerably. In August 1973, he developed paraesthesiae, numbness, and clumsiness in the right hand which cleared spontaneously over several days. In October 1973, he noted the onset of blurred vision in the right eye, as well as pain in the eye that was exacerbated by upward and right lateral gaze. He was readmitted to Georgetown University Hospital two days later by which time visual acuity in the right eye was 20/200. The fundi appeared normal but he had a large central scotoma in the visual field of the right eye, as well as central facial weakness on the left side. He was started on a two week course of intramuscular corticotrophin (ACTH) but visual acuity continued to deteriorate and he received a single retrobulbar injection of betamethasone $(6 \mathrm{mg})$ and a three day course of intravenous priscoline $(25 \mathrm{mg} /$ day). By the time of discharge two weeks later, the patient had no light perception and no pupillary constriction to light in the right eye.

The patient was readmitted to Georgetown University Hospital one week after discharge because of severe right eye pain exacerbated by movement of the eye in any direction. Examination revealed complete blindness in the right eye as well as blurring and 


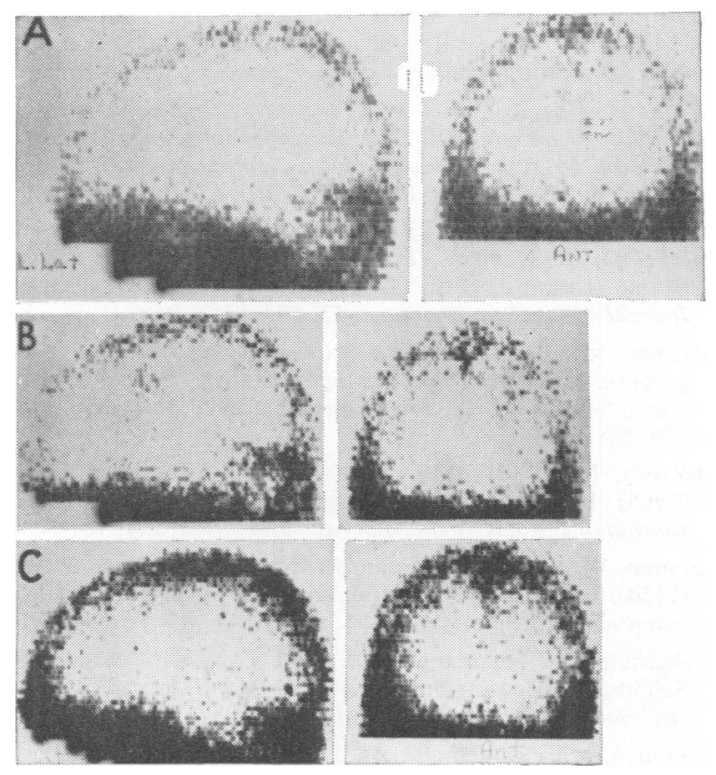

FIGURE $A{ }^{99}$ Tc brain scan, A in June 1973 which is normal, B in October 1973 showing an area of increased uptake in the left superior parietal region, and $\mathrm{C}$ in November 1973 in which the abnormal area of increased uptake is no longer present.

hyperaemia of the right optic disc. Repeat skull radiographs, including optic foramen views and optic canal tomograms, were normal, but a ${ }^{99} \mathrm{Tc}$ brain scan revealed an area of increased uptake in the left superior parietal region which was confirmed on a repeat brain scan the following day (Figure, B). Repeat lumbar puncture revealed opening pressure of $160 \mathrm{~mm} \mathrm{CSF}$, sugar $56 \mathrm{mg} / 100 \mathrm{ml}, 9$ lymphocytes per $\mathrm{mm}^{3}$, and protein $40 \mathrm{mg} / 100 \mathrm{ml}$, gamma globulin $16 \%$, negative VDRL, and negative FTA. Selective cerebral angiography of both internal carotid arteries and the right vertebral artery failed to reveal any abnormality. The patient was discharged one week later, by which time visual acuity had improved to $20 / 100$ in the right eye with decreased swelling and hyperaemia of the right optic disc. Repeat brain scan four weeks after the abnormal scans was within normal limits (Figure, C).

A review of 38 additional patients at Georgetown University Hospital with a diagnosis of multiple sclerosis revealed that, except for the present case, all had normal brain scans.

\section{DISCUSSION}

In the vast majority of cases with multiple sclerosis brain scans are negative (Overton et al., 1965; Gold and Loken, 1969; Gize and Mishkin, 1970; Moses et al., 1972), which is in agreement with the finding of only one positive scan in 38 patients with multiple sclerosis. It appears from the available case histories in the literature and the present case that positive scans have occurred only during acute exacerbations of multiple sclerosis (Seaman et al., 1954; Overton et al., 1965; Gize and Mishkin, 1970). In only one previous case (Gize and Mishkin, 1970) has a follow-up scan been reported as normal, but to our knowledge the present case is the only one reported in which a normal brain scan has been previously documented. The four week period between scans in the present case and that of Gize and Mishkin suggests that within this period of time the integrity of the blood brain barrier is restored. That acute changes occur in blood brain barrier in multiple sclerosis have been demonstrated (Broman, 1964) and appear to be well correlated with the ultrastructural demonstration of perivenular and astrocytic oedema in acute lesions (Lumsden, 1970).

There are probably several reasons why positive brain scans are not seen more frequently in multiple sclerosis: (1) few clinicians order brain scans once a clinical diagnosis of multiple sclerosis is established, (2) the scan probably has to be performed during an acute exacerbation, and (3) the acute lesions probably have to be larger than $2 \mathrm{~cm}$ in diameter (Krishnamurthy et al., 1972) to be detected, and acute lesions of this size are not the ones most commonly seen. Parenthetically, it is of interest that, despite a sizeable brain scan lesion in the left parietal region, no recent symptoms or clinical signs could be elicited referable to the region of the abnormality in the present case. This demonstrates that the failure of sizeable, acute demyelinating lesions to produce clinical signs or symptoms is not necessarily due to their being located in clinically silent areas of the central nervous system. Positive brain scans might be seen with far greater frequency if they were performed more often on patients with multiple sclerosis. It should be emphasized that multiple sclerosis is a part of the differential diagnosis of 
a positive brain scan, particularly in the younger adult patient population. Furthermore, in patients within the appropriate age range who present clinically with a single, focal lesion of the central nervous system, a focal brain scan abnormality not referable to a site appropriate to the clinical findings may strongly suggest the diagnosis of multiple sclerosis.

\section{REFERENCES}

Antunes, J. L., Schlesinger, E. B., and Michelsen, W. J. (1974). The abnormal brain scan in demyelinating diseases. Archives of Neurology, 30, 269-271.

Bady, B., Trillet, M., Boucher, M., and Gallade (1969). A propos d'observations de scléroses en plaques avec signes gamma-graphiques pseudo-tumoraux. Revue d'Oto- NeuroOphtalmologie, 41, 369-373.

Broman, T. (1964). Blood-brain barrier damage in multiple sclerosis. Supravital test-observations. Acta Neurologica Scandinavica, 40, suppl. 10, 21-24.

Gize, R. W., and Mishkin, F. S. (1970). Brain scans in multiple sclerosis. Radiology, 97, 297-299.

Gold, L. H. A., and Loken, M. K. (1969). Retrospective evaluation of isotope images of the brain in 852 patients. Radiology, 92, 1473-1476.
Krishnamurthy, G. T., Mehta, A., Tomiyasu, U., and Blahd, W. H. (1972). Clinical value and limitations of ${ }^{99 m} \mathrm{Tc}$ brain scan: an autopsy correlation. Journal of Nuclear Medicine, 13, 373-378.

Lumsden, C. E. (1970). The neuropathology of multiple sclerosis. In Handbook of Clinical Neurology, pp. 217-309. Edited by P. J. Vinken and G. W. Bruyn. North-Holland: Amsterdam.

Moses, D. C., Davis, L. E., and Wagner, H. N., Jr (1972). Brain scanning with ${ }^{99 m} \mathrm{TcO}_{4}-$ in multiple sclerosis. Journal of Nuclear Medicine, 13, 847-848.

Mosher, M. B., Schall, G. L., and Wilson, J. (1971). Progressive multifocal leukoencephalopathy. Positive brain scan. Journal of the American Medical Association, 218, 226-228.

Overton, M. C., III, Haynie, T. P., and Snodgrass, S. R. (1965). Brain scans in nonneoplastic intracranial lesions. Journal of the American Medical Association, 191, 431-436.

Seaman, W. B., Ter-Pogassian, M. M., and Schwartz, H. G. (1954). Localization of intracranial neoplasms with radioactive isotopes. Radiology, 62, 30-36.

Valenstein, E., Rosman, N. P., and Carter, A. P. (1971). Schilder's disease. Positive brain scan. Journal of the American Medical Association, 217, 1699-1700.

Williams, J. L., and Beiler, D. D. (1966). Brain scanning in nontumorous conditions. Neurology (Minneap.), 16, 11591166. 